\title{
Comunicación y productividad en pequeñas y medianas empresas de un cluster textil en Colombia ${ }^{1}$
}

\author{
Mario Humberto Muñoz \\ Hernández. \\ Universidad de Antioquía \\ mmunoz@economicas.udea. \\ edu.co
}

${ }^{1} \mathrm{El}$ presente artículo es producto de la investigación " $\mathrm{La}$ comunicación en las organizaciones: su incidencia en la productividad y en la satisfacción en el trabajo", que está inscrita en el grupo de investigación Imark del Centro de Investigaciones y Consultorías (CIC) de la Facultad de Ciencias Económicas de la Universidad de Antioquía (Colombia) y en el Comité de Desarrollo de la Investigación, (CODI) de la misma Universidad. Para realizar el trabajo de campo se tuvo la colaboración del doctor Lucas Giraldo, subdirector de ACOPI Antioquia. El autor agradece a Daniela Rico Balvín, quien estuvo vinculada como estudiante de pregrado en formación investigativa.

\section{Resumen}

El artículo analiza la opinión que tienen los gerentes y obreros sobre la comunicación y su incidencia en la productividad. El estudio consiste en una encuesta aplicada a una muestra de 17 empresas de un cluster textil en Colombia. Estas empresas fueron seleccionadas por conveniencia de un listado de $36 \mathrm{em}-$ presas de la Asociación Colombiana de las Micros, Pequeñas y Medianas empresas (ACOPI, Antioquía). Como se muestra en el artículo, los gerentes y los obreros opinan que la comunicación directa, las conversaciones y las reuniones tienen una relación con el crecimiento de la productividad.

Palabras clave: comunicación, conversaciones, reuniones, Pymes, productividad.

Clasificación JEL: M11, M15 


\title{
Communication and productivity in small and medium sized businesses of a textile cluster in Colombia
}

\begin{abstract}
The paper analyzes the view of managers and workers about communication and its influence in productivity. The study consists of an applied survey to a 17 companies sample from a textile business cluster in Colombia. These companies were selected from a list of 36 companies of the Asociación Colombiana de las Micros, Pequeñas y Medianas Empresas (ACOPI, Antioquia). As shown in the paper, the managers and the workers believe that face to face communication, talks and meetings have a close relation to productivity's growth.
\end{abstract}

Keywords: Communication, talks, meetings, small and medium sized bussiness SMBs, productivity.

\section{Introducción}

El presente artículo es el resultado de la investigación "La comunicación en las organizaciones: su incidencia en la productividad y en la satisfacción en el trabajo"; con ella se pretende hacer una reflexión crítica sobre los procesos de comunicación en las organizaciones, la cual está fundamentada epistemológicamente desde las ciencias humanas, donde se reconoce al hombre como sujeto de carácter multidimensional y complejo. Este trabajo permite ver las creencias que tienen los gerentes y obreros de 17 empresas sobre la relación entre productividad y comunicación en las organizaciones.

Se debe reconocer que la comunicación no es la única variable que incide en la productividad, sino que también está asociada con otras variables como: métodos y equipo, utilización de la capacidad de los recursos y los niveles de desempeño, Bain (1993). Del mismo modo, Hellweg y Phillips (1982) sostienen que la comunicación ha sido medida en diferentes estudios en formas distintas, por ejemplo, como satisfacción de la comunicación, como efectividad de la comunicación del supervisor y como comunicación empresarial. Varios investigadores conciben la comunicación como una variable multidimensional en el contexto organizacional.

Ahora bien, surgen preguntas alrededor de si la comunicación formal incide más que la informal en la tasa de crecimiento de la productividad; además, se indaga 
cómo se relacionan la interacción comunicativa, la participación y la integración en el trabajo; y si se está de acuerdo con Miller y Monge (1986) quienes sostienen que los efectos de la participación de los operarios en el incremento de la productividad son altos. También emergen interrogantes sobre cómo inciden los medios de comunicación utilizados por los directivos de las Pymes en la productividad y cuáles son las fuentes de información preferidas por los operarios.

Quizás la pregunta más utilizada entre los estudiosos de la comunicación hace referencia a los factores que intervienen en el proceso comunicativo y a los diferentes efectos en las actitudes en los operarios de la organización; dichos factores y su influencia se encuentran en el esquema lineal de comunicación sugerido por Lasswell (1948): "Quién dice qué, mediante qué canal, a quién, con qué efectos".

Los resultados de la presente investigación podrían servir para que las Pymes reconozcan la importancia de la incidencia de la comunicación formal e informal en la tasa de incremento de la productividad.

\section{Marco teórico}

\section{La comunicación y la organización}

En palabras de Costa (1999), "Existe un nuevo paradigma para pensar y gestionar la organización. Este nuevo paradigma implica la fusión de las ciencias empresariales clásicas (Economía, Organización, Administración y Productividad) y las ciencias de la Comunicación o de la Información y de la acción, con el acento puesto en la sociología y la teoría de sistemas. Y fecundado todo este paradigma nuevo por lo progresos tecnocientíficos (...) No se pueden considerar las actuaciones de la organización (empresa) con independencia de la comunicación, ni a la inversa, la comunicación independientemente de las actuaciones, las realizaciones y los hechos".

En este sentido, el advenimiento del estudio de la comunicación en las organizaciones, como disciplina, es de vigencia reciente y tiene su origen en las necesidades prácticas y teóricas de las empresas, las cuales emergen académicamente por una doble vía: en el intento de mejorar las competencias comunicativas de los distintos actores sociales que intervienen en el ciclo productivo y en la evolución de la teoría organizacional, cada vez más centrada en las ciencias humanas; por ejemplo, se observa la transición de la teoría de las organizaciones, influida por la sociología, a los estudios organizacionales (EO), más influidos por la antropología social. 
Gusdorf (1957) propone una de las concepciones más sólidas de la comunicación en la organización: se entiende ésta como el proceso de la búsqueda del tú por parte del yo para confluir en el nosotros, lo anterior se asemeja a una tensión entre el mundo interior y exterior del sujeto; o en palabras de Freud, se da una tensión entre el individuo y la sociedad. También diferencia entre expresión y comunicación y concibe la primera como la manifestación más natural de la individualidad que no reconoce la censura, y la segunda es aquella que le permite al sujeto ejercer su dimensión social. Se deduce que todo acto de lenguaje compromete un sujeto comunicante (emisor) y otro interpretante (receptor), en posiciones móviles, pero que han de tener en común universos de referencia. En este contexto, la alteridad se entiende como el reconocimiento del otro en las interacciones comunicativas y, por lo tanto, la organización es un espacio de alteridad donde nos reconocemos y nos construimos como sujetos humanos pensantes.

Una mirada sobre la intencionalidad de la comunicación consiste en que no es posible dejar de comunicar y entonces surge la pregunta: ¿Existe un comportamiento que no sea comunicativo? Es obvio que si no hay nadie a su alrededor se encontrará con la vieja pregunta: "El árbol que cae en el bosque, ¿hace ruido si no hay nadie para oírlo?". Para que haya comunicación es necesario, por lo menos, la presencia de otra persona (Bateson, 1994); la intencionalidad es un componente esencial de todo tipo de comunicación porque es la que permite que el sujeto humano - llámese emisor o receptor — se organice y hace posible que las personas coordinen sus actividades para lograr objetivos comunes. La comunicación es una fuerza dominante en la vida organizacional y es el sistema nervioso de toda organización.

La comunicación ha sido abordada por la teoría administrativa y la teoría de organizaciones, dos teorías profusamente entrelazadas, pero sustancialmente diferentes, desde una concepción lineal, racional y utilitarista; ellas acogen el esquema lineal de comunicación de Shannon que se caracteriza por privilegiar el concepto de información en su magnitud estadística y por calificar el mensaje independientemente de su significación.

El modelo clásico o funcional de comunicación busca de forma exclusiva mantener la integridad material del mensaje a lo largo del proceso de comunicación. No ha estado dentro de las preocupaciones de sus defensores, ni dentro del contexto del modelo, indagar sobre la interpretación del mensaje ni tener en cuenta sus posibles efectos sobre los destinatarios, aunque estas dos di- 
mensiones constituyen los elementos fundamentales de toda comunicación humana. En dicho modelo, emisor y receptor son concebidos como individuos ${ }^{2}$ aislados, unos destinatarios homo economicus racionales y nunca entendidos bajo el enfoque holístico del estudio del sujeto humano. ${ }^{3}$

La racionalidad instrumental de la comunicación en la organización se puede apreciar en Fernández (1991) cuando arguye que aquélla se entiende como un conjunto de técnicas y actividades encaminadas a facilitar y agilizar el flujo de mensajes que se dan entre los miembros de la organización, así como entre la organización y su medio, con el fin de que esta última cumpla y resuelva sus objetivos estratégicos de crecimiento, rentabilidad y supervivencia; pero existen otras visiones disciplinares llenas de humanismo sobre la comunicación en las organizaciones.

Un primer enfoque es defendido por Bateson (1994) quien piensa desde afuera ${ }^{4}$ - un afuera desprovisto de todo afán de lucro, productividad y eficiencia- y propone que "En general, la comunicación puede definirse como el sistema de comportamiento integrado que calibra, regulariza, mantiene y, por ello, hace posibles las relaciones entre los hombres", en consecuencia, podemos ver en la comunicación el mecanismo de la organización social, de la misma manera que la transmisión de la información es el mecanismo del comportamiento comunicativo. Un segundo enfoque lo presenta Costa (1999) quien sostiene que "Toda acción, todo acto, significa, y con ello comunica. Incluso con independencia de la voluntad de quien lo hace. Y toda comunicación es una acción, un modo de actuar de unos con otros [...]". Sin embargo, y a pesar de estas evidencias, los teóricos de

\footnotetext{
${ }^{2} I b a ́ n ̃ e z$, contrario a la noción de individuo que resulta conveniente para quienes administran, propone la emergencia de la subjetividad que sólo es posible mediante interacciones lingüísticas de tipo conversacional. El individuo se refiere a una sola entidad, separada de una colectividad, y se ha naturalizado para referir objetos animados e inanimados, humanos y cosas. La subjetividad sugiere cristalizar en la práctica una filosofía de gestión que tenga al hombre por el sujeto y el fin de toda acción productiva o comercial y no por su medio u objeto. Véase Jesús Ibáñez, El regreso del sujeto. La investigación social de segundo orden, Madrid: Siglo XXI, 1994. ${ }^{3}$ Para Edgar Morin, el hombre es sujeto humano porque se constituye a partir de tres niveles de emergencia: el cuerpo-sujeto, como organismo que se auto-organiza de manera auto-referente y auto-céntrica; el cerebro-psique como sistema neurocerebral inseparable del cuerpo-sujeto; y la conciencia como expresión de la individualidad del hombre. El sujeto no constituye ni una esencia ni una sustancia; se trata de una modalidad de ser, propia del individuo viviente. Véase Edgar Morin, El método II: la Vida de la Vida. Madrid: Cátedra, 1993.

${ }^{4}$ Gregory Bateson fue investigador de la Escuela de Palo Alto, una pequeña ciudad en el extrarradio de San Francisco; también es conocida como Universidad Invisible, que se fundó en el año 1942 con Bateson, quien se asocia con Ray Birdwhistell, Edward Hall, Irving Goffman y Paul Watzlawick. Ellos proponen una alternativa al modelo lineal de comunicación y trabajan a partir del modelo circular retroactivo o de estudio de la comunicación humana.
} 
la organización, del management, de la comunicación incluso, las empresas y las ciencias empresariales han ignorado la ciencia de la comunicación durante más de medio siglo a favor exclusivo de la ciencia económica y la administración; además, igualmente parecen haber ignorado que la naturaleza misma de la acción implica, quiérase o no, comunicación, pues una se contiene en la otra. Para Costa, la disyunción entre la acción productiva y la acción comunicativa proviene de la obsesión fabril, de moda en occidente, que relegó la comunicación a un subproducto de la actividad considerada fundamental de la empresa: producir. Un tercer enfoque, desde las ciencias humanas, lo presenta Van Dijk (2000) al argumentar que el administrador en las organizaciones debe estar capacitado para entender cómo se usa el lenguaje y cómo interactúan y piensan los sujetos discursivos; más importante aún es que el análisis del discurso proporciona las herramientas teóricas y metodológicas necesarias para generar un enfoque crítico sobre la relación entre el poder y las comunicaciones en la organización.

Ahora bien, ¿cómo se relaciona la comunicación con la organización? Se puede entender que "El hombre es un animal que habla y el lenguaje no existe antes de la iniciativa personal que lo pone en movimiento" (Gusdorf, 1957). Dicho en palabras de la modernidad ${ }^{5}$ : el hombre no existe fuera de las prácticas discursivas; de igual forma, no se puede comprender la acción en la organización independiente de la interacción comunicativa y tampoco es posible entender la interacción comunicativa separada de las actuaciones en la organización.

Del mismo modo, Morin (1993) está de acuerdo que cada ser viviente es un emisor y receptor a la vez. A partir de esta díada se teje una red de comunicaciones con el entorno, la cual se ramifica en un conjunto de redes e interfaces que constituyen el tejido comunicacional de la nueva organización virtual; ésta se caracteriza por la interacción del emisor y receptor con Internet, los dispositivos tecnológicos y las nuevas herramientas de comunicación.

Una crítica sobre el modelo lineal de comunicación y la subordinación de éste al mandamiento de la gestión la presenta Morin cuando argumenta que "A decir

\footnotetext{
${ }^{5}$ La Real Academia Española define la modernidad como cualquier tiempo considerado contrapuesto a lo clásico, pero acá privilegiamos el concepto de modernidad de Foucault, entendido como actitud más que un periodo histórico y a la vez es una manera de sentir, actuar y elucubrar. Para algunos teóricos, la administración como invento de la modernidad es lógico que responda a un ethos particularmente enmarcado en una racionalidad de tipo instrumental (ver www.rae.es).
} 
verdad, Shannon y Weaver no sólo pusieron juntos el mandato y la comunicación, cosa que se impone a toda la teoría organizacional: subordinaron la comunicación al mandato, de ahí el término cibernética que define la nueva ciencia".

La comunicación no se agota en el mensaje; ella es tensa, densa, irritante, fascinante y es ante todo un sistema que ocurre en un contexto temporal, complejo y espacial. La estructura de la significación es muy importante, pero más allá de ella, e incluso para poder dar cuenta de ella, es necesario ver quién responde (emisor-receptor) y qué hace éste con el mensaje. El pensamiento moriniano sugiere que los grandes temas de la humanidad son transversales y planetarios; por lo consiguiente, la incertidumbre y la complejidad son los elementos naturales del desarrollo humano en la organización moderna.

En el ambiente colombiano Múnera (2005) señala que "el campo de encuentro entre la comunicación y organización es la administración. Al serle fiel a su etimología, la comunicación es ética por excelencia; legitima a la organización como cuerpo y como metáfora integradora; lucha por articular trabajo y mundo de la vida en un hecho social total; propende por organizaciones viables. Caso contrario, si traicionan su etimología, comunicación, organización y administración, seguirán marchando contra la sociedad".

En lenguaje metafórico, los teóricos de la organización han observado la naturaleza para entender la vida organizacional, la administración y las comunicaciones y, en consecuencia, la organización como corpus que integra los conceptos de funciones orgánicas, relaciones con el entorno, relaciones entre especies y, por último, la comunicación. Con base en lo anterior, se puede mencionar que el mundo de hoy es un universo de organizaciones y, por consiguiente, administrado.

En general, según Lucas (2003), se puede aceptar la existencia de dos formas o dos distintas etapas evolutivas de la comunicación en la organización: 1) El modelo lineal de comunicación, funcionalista o metáfora del telégrafo; en este enfoque se destaca el transporte de información y se confunde ésta con la comunicación, además de que se ve al receptor como un ente pasivo; en el modelo se encuentran autores como Lasswell (descriptivo), Shannon y Weaver (matemático) y Jakobson (ingenieril). 2) El modelo circular o metáfora orquestal de la comunicación; en este enfoque se destaca la ida y vuelta del contenido y hace a la comprensión el fin de la comunicación; sus autores más representativos son Schramm (personal y de masas), De Fleur (simultáneo) y Bateson. 


\section{La comunicación y la productividad}

Existen las siguientes conjeturas en la comunidad académica sobre la relación que puede existir entre la comunicación y la productividad: "A mayor exactitud de la información y las opiniones generadas en las organizaciones mayor será la productividad y por tanto, la comunicación eficaz y los rendimientos elevados van de la par" (Blum y Naylor, 1977).

Según Clampitt y Downs (1993) la satisfacción de los empleados y su rendimiento están correlacionados fuertemente con los procesos de comunicación interna y se acepta que el tipo de organización, por ejemplo, si es una empresa manufacturera o de servicios, puede modificar la relación entre comunicación y productividad. También afirman que "algunos investigadores han examinado el impacto de la comunicación supervisor/subordinado en la productividad. Se ha demostrado que la productividad más alta es asociada con una retroalimentación más efectiva sobre el desempeño. Normalmente los supervisores son los responsables de esta retroalimentación, por eso, no es sorprendente que muchos investigadores han indicado que la efectividad de la comunicación de los supervisores está relacionada con la productividad del empleado".

Las conjeturas de Kersley y Martin (1997) establecen una correlación entre la comunicación y el crecimiento de la productividad; ellos proponen tres preguntas para resolver: 1) ¿podemos explicar la asociación entre la comunicación y el crecimiento en la productividad?, 2) ¿se puede explicar por qué la comunicación informal tiene un efecto más grande en la productividad que la comunicación formal?, 3) si la comunicación es beneficiosa ¿por qué no todas las empresas se comunican oportunamente con sus operarios?

¿Qué significa el concepto de productividad? La productividad según Bain (1993) no es sólo una medida de la producción ni la cantidad de bienes que se ha fabricado; es una medida de lo bien que se han combinado y utilizado los recursos para cumplir los objetivos específicos deseables.

Para Clampitt y Downs (1993) en las organizaciones manufactureras existen los siguientes significados de productividad: eficiencia, calidad, cantidad, la relación calidad/cantidad, el alcance de objetivos, se puede hacer mejor y valor agregado. En términos estratégicos, la productividad consiste en producir por encima del 
promedio y en satisfacer plenamente a los consumidores utilizando de la mejor manera posible todos los recursos disponibles.

Se suele pensar que los trabajadores poseen información que es potencialmente valiosa para la empresa y que ellos usualmente hacen sugerencias que podrían incrementar la productividad o reducir los costos; sin embargo, esta información sólo es útil si es transmitida a la dirección de la empresa. Para que lo anterior ocurra, los trabajadores deberían tener más contacto con la organización y así la comunicación llevaría a un mayor crecimiento en la productividad. Asimismo, se esperaría que el trabajador tuviera mayor capacidad de transmitir ideas y sugerencias cuando la comunicación es menos formal y ocurre cerca al lugar de trabajo. Lo anterior podría explicar por qué la comunicación informal es más efectiva que la formal y a su vez por qué los círculos de calidad son la forma más efectiva de la comunicación informal.

Kersley y Martin también afirman que los resultados de sus hallazgos significan que la comunicación entre las empresas y sus trabajadores incide en una tasa de crecimiento más rápida de la productividad. Además, existe una clara asociación entre la comunicación directa y el trabajador y un aumento de la productividad; sin embargo, diferentes formas de comunicación tienen diferentes efectos. El más fuerte de ellos procede de la comunicación informal de doble vía, descentralizada y propiciadora de un ambiente de participación para el trabajador; otras formas de comunicación informal tienen un efecto más pequeño, pero positivo.

¿Cómo se podría aumentar la comunicación informal? Solicitar a las empresas comunicarse más con sus operarios es poco probable que sea efectivo; los resultados de Kersley y Martin sugieren que el elemento clave en la comunicación es la transmisión de la información de los trabajadores a los directivos.

Hellweg y Phillips (1982) sostienen que pocos estudios han incorporado visiones multidimensionales de la productividad y que existen numerosas variables organizacionales que pueden mediar la relación entre ésta y la comunicación; además, podría existir una diferencia en la relación basada en el nivel del empleado involucrado, el tipo de trabajo - ya sea mecánico o creativo- y si su desempeño es muy dependiente de la información; de igual manera, el tamaño de la organización puede ser un factor que incida en la relación entre comunicación y productividad. 


\section{Metodología de investigación}

En esta investigación se aplicó una encuesta a 17 gerentes (ver Anexo 1) y a 15 operarios (ver Anexo 2) de 17 empresas que se seleccionaron por conveniencia de una lista de 36 de Pymes del cluster Textil/Confección, Diseño y Moda ubicadas en el área metropolitana de Medellín, Colombia, afiliadas a ACOPI (ver Anexo 3). El objetivo de la encuesta aplicada a gerentes fue recoger las opiniones de ellos sobre cómo incide y se mide la productividad en las Pymes, así como, indagar la forma en que incide la comunicación formal e informal en la productividad e indagar la incidencia de los medios de comunicación y la interacción comunicativa en la productividad. La encuesta, tipo escala de Likert, aplicada a los operarios tuvo como objetivo caracterizarlos demográficamente y obtener sus opiniones sobre las fuentes de información preferidas. En el análisis y procesamiento de datos se utilizó el programa estadístico Statistical Package for the Social Sciences (SPSS).

\section{Resultados}

Los resultados se presentan globalizados en las Pymes, ya que no es posible, debido a la clasificación de ACOPI, hacer un análisis diferenciado de información entre pequeñas y medianas empresas.

\section{Caracterización sociodemográfica de los operarios de las Pymes}

Las variables sociodemográficas más relevantes de los operarios de las organizaciones en estudio muestran una amplia feminización del trabajo operativo de las Pymes del cluster Textil/Confección, Diseño y Moda de Medellín, Colombia. El $85.7 \%$ de la población encuestada son mujeres y el $14.3 \%$ son hombres; respecto a la variable estado civil, el porcentaje más alto corresponde a solteros, con un $42.9 \%$, puede observarse como la unión libre y la separación son categorías en crecimiento: el $14.3 \%$ corresponde a personas en unión libre y el $7.1 \%$ a separados; el $35.7 \%$ son casados.

En la población de operarios encuestados existe una media de 6.54 años como tiempo de vinculación en las Pymes; además, la madurez es una característica de los operarios: el 78.6\% de los encuestados es mayor de 36 años. La contratación laboral a término fijo es una característica creciente en la economía colombiana y más concretamente en la pequeña y mediana industria: el 35.7\% de los encuestados está contratado a término fijo. 
Con respecto al nivel de escolaridad, el $61.5 \%$ de los operarios cuenta con estudios de secundaria, el $23.1 \%$ tiene escolaridad técnica, el $7.7 \%$ tiene estudios tecnológicos y el otro $7.7 \%$ sólo cuenta con estudios de educación primaria.

\section{Cómo incide la comunicación en la productividad}

$\mathrm{Al}$ analizar los datos, se encuentra que el $41.2 \%$ de los gerentes encuestados opina que la comunicación incide en el aumento de la productividad, el 23.5\% dice que la comunicación incide en la planeación más clara de las tareas, un 17.6\% de la población encuestada manifiesta que mejora la eficiencia, otro $11.8 \%$ afirma que la comunicación permite mejorar el flujo de información de doble vía entre el emisor y el receptor, mientras que 5.9\% dice que incide en el mejoramiento de la calidad. El anterior resultado, conjuntamente con la eficiencia, está relacionado directamente con el concepto de productividad.

La calidad y la productividad son variables compatibles, ya que existen menos procesos y no hay tantos desperdicios; lo anterior significa la siguiente relación en cadena: al mejorar la calidad, se mejora el servicio, se reducen los costos y los empleados están más satisfechos con su trabajo. De este modo, se incrementa la productividad y se es, adicionalmente, más competitivo.

\section{Cómo se mide la productividad en las Pymes}

De acuerdo con la opinión de los gerentes encuestados, el $47.1 \%$ señala que la productividad se mide mediante la relación productividad/hora-hombre, entendida como la relación entre la producción y el personal ocupado o en términos aritméticos es aquella que resulta de dividir la producción entre las horas-hombre trabajadas.

La cultura de no medir la productividad, expresado por el 11.8\% de los encuestados y como se observa en el gráfico 1 , se debe en gran medida a la existencia de una gerencia poco capacitada en temas relacionados con la administración y la productividad.

¿Por qué es importante medir la productividad, en las Pymes? Porque al medirla se sabe si se puede incrementarla; además, los principales beneficios de un mayor incremento de la productividad son, en gran parte, del dominio público: es posible producir más en el futuro, usando los mismos o menores recursos, y la calidad de 
vida de los operarios podría elevarse ya que si ellos producen más las Pymes rentan más; al rentar más, la empresa puede capacitar a sus empleados, pagar mejores salarios y establecer una política de promoción laboral, vinculando a los mejores operarios de término fijo a contrato indefinido. Se acepta en teoría que el incremento de la productividad en las Pymes es la única forma de mantener incrementos en los salarios reales y, además, es una manera de alcanzar una mayor competitividad en un mundo más globalizado.

\section{Gráfico 1}

¿Cómo se mide la productividad en las Pymes?

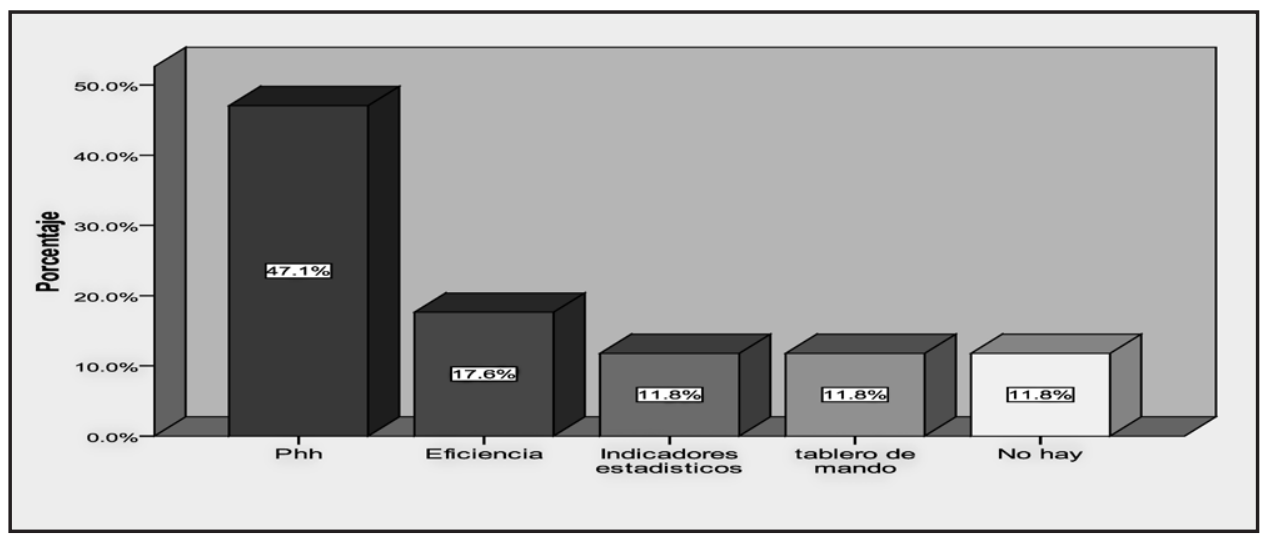

Fuente: Encuesta a gerentes: incidencia de la comunicación en la productividad en las Pyme del cluster Textil/Confección, Diseño y Moda del área metropolitana de Medellín, Colombia.

Qué clase de comunicación incide más en la tasa de crecimiento de la productividad

Como se observa en el cuadro 1, los gerentes encuestados le dan un porcentaje muy similar a la incidencia de la comunicación formal e informal en el aumento de la productividad: el $53 \%$ afirma que la comunicación formal incide en la productividad, mientras que un $47 \%$ de los encuestados dice que es la comunicación informal la que incide en la productividad. La comunicación formal sigue vigente por permitir guardar el registro y por su rigidez (35.3\%) y por facilitar el control (17.6\%); por otro lado, la comunicación informal mejora el diálogo (17.6\%), es la más acostumbrada (17.6\%) y ella rompe la línea jerárquica en las estructuras burocráticas de la organización (5.9\%). La comunicación formal e informal es parte de la paradoja que se vive en la organización: por un lado, representa la cooperación 
humana, pero también es simultáneamente un sistema de control que propicia las conductas basadas en sumisión y obediencia de los subordinados.

\section{Cuadro 1}

\section{¿Qué clase de comunicación incide más en la tasa de crecimiento de la productividad?}

\begin{tabular}{|l|l|l|l|}
\hline \multirow{2}{*}{ ¿Por qué? } & \multicolumn{2}{|c|}{ Tipo de comunicación } & \multirow{2}{*}{ Total } \\
\cline { 2 - 3 } & La comunicación formal & $\begin{array}{l}\text { La comunicación } \\
\text { informal }\end{array}$ & $17.6 \%$ \\
\hline Costumbre & $.0 \%$ & $17.6 \%$ & $23.5 \%$ \\
Fácil control & $17.6 \%$ & $5.9 \%$ & $17.6 \%$ \\
Mejora el diálogo & $.0 \%$ & $17.6 \%$ & $5.9 \%$ \\
Rompe la línea jerárquica & $.0 \%$ & $5.9 \%$ & $35.3 \%$ \\
Rigidez y registro & $35.3 \%$ & $.0 \%$ & $100 \%$ \\
Total & $53 \%$ & $47 \%$ & \\
\hline
\end{tabular}

Fuente: Encuesta a gerentes: incidencia de la comunicación en la productividad en las Pyme del cluster Textil/Confección, Diseño y Moda del área metropolitana de Medellín, Colombia.

\section{Medios de comunicación en las empresas y su incidencia en la productividad}

Del gráfico 2 se destaca que la mayoría de los gerentes opina que la mayor incidencia sobre la productividad la tiene la comunicación directa o cara a cara, en este caso el contacto personal y la reunión, que privilegia el diálogo y la doble vía entre operario y directivo. Como fruto de la modernidad aparece el correo electrónico, que desplaza al teléfono como medio personal, para incidir en el aumento de la productividad, junto a este medio sigue vigente otro antiguo y tradicional: el memorando.

Siguiendo con la comunicación directa, Aktouf (1996) enfatiza en la importancia de la comunicación en general y de la comunicación directa, verbal en particular, en las organizaciones; se sabe que Fayol (1986) proscribía sistemáticamente lo escrito y lo formal cuando éstos podrían reemplazarse por el diálogo directo: "El habla y los hechos de habla son como una de las llaves de tuerca del trabajo del administrador". El comentario original de Fayol hace referencia a que para tratar asuntos de negocios o para dar una orden que será completada mediante explicaciones, es generalmente más simple y más rápido proceder oralmente que por escrito. Es sabido, por otra parte, que los conflictos o equívocos que se podrían solucionar en una conversación se enconan, a menudo, por el uso de la correspondencia y memorandos. 


\section{Gráfico 2}

Medios de comunicación en las empresas y su impacto en la productividad

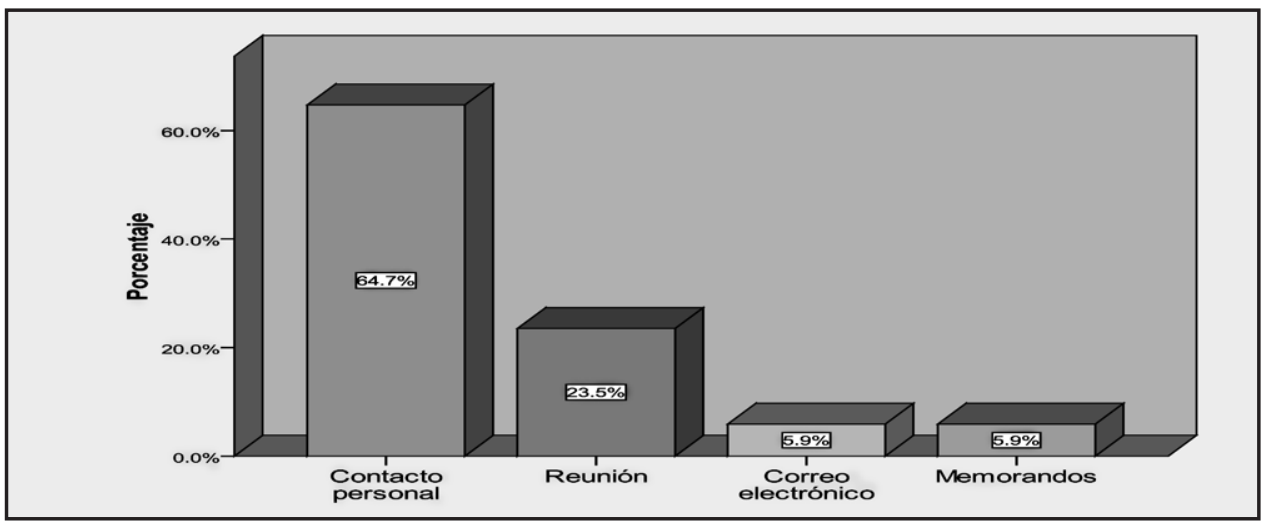

Fuente: Encuesta a gerentes: incidencia de la comunicación en la productividad en las Pyme del cluster Textil/Confección, Diseño y Moda del área metropolitana de Medellín, Colombia.

\section{La interacción comunicativa y su incidencia en la productividad en las Pymes}

Un alto porcentaje de los gerentes encuestados $(82.3 \%)$ indica que las interacciones comunicativas sí inciden en la productividad porque mejora la participación entre compañeros y aumenta el compromiso de los grupos de trabajo; el resto (17.7\%) opina que las interacciones comunicativas no inciden en la productividad debido a la pérdida de tiempo (ver cuadro 2).

Ahora, ¿qué es la interacción comunicativa? ${ }^{6}$ Rizo (2004) nos ofrece una respuesta al señalar que "Es sabido que la comunicación puede entenderse como la interacción mediante la que gran parte de los seres vivos acoplan sus respectivas conductas frente al entorno mediante la transmisión de mensajes, signos convenidos por el aprendizaje de códigos comunes". Las interacciones comunicativas se realizan cara a cara, cuerpo a cuerpo y enmarcadas en un espacio y tiempo determinados; los sujetos se involucran necesariamente para que pueda existir dicha interacción, lo cual es una condición necesaria para que exista la vida social.

${ }^{6}$ Para Irving Goffman (2001), la interacción comunicativa se puede entender como "La influencia recíproca de un individuo sobre las acciones de otro cuando se encuentran ambos en presencia física inmediata" (p. 27). 
Sobre la interacción comunicativa y los grupos de trabajo en las Pyme se puede aseverar lo siguiente: los grupos que son más productivos tienen establecida una red de comunicaciones más adecuada que aquellos que son menos productivos; existe una mayor participación del grupo, aumento de la productividad y satisfacción en el trabajo cuando los integrantes sienten que tienen el derecho de intervenir en la discusión y donde se proveen los medios para concesiones mutuas entre los líderes y los otros miembros del grupo. Las iniciativas que incrementan la comunicación inciden en el crecimiento en la productividad, pero serán más efectivas si se aumenta la cantidad de comunicación informal, descentralizada y propiciadora de un ambiente de participación y compromiso para el trabajador. La interacción comunicativa incentiva la productividad cuando existen redes de comunicación, trabajo en equipo entre los operarios y satisfacción en el puesto de trabajo.

\section{Cuadro 2}

¿Incide la interacción comunicativa en la productividad?

\begin{tabular}{|l|l|l|}
\hline \multirow{2}{*}{ ¿Por qué? } & \multicolumn{2}{|c|}{ Respuesta } \\
\cline { 2 - 3 } & No : $17.7 \%$ & Sí : $82.3 \%$ \\
\hline Aumenta el compromiso de los & $.0 \%$ & $28.5 \%$ \\
grupos de trabajo & & \\
Mejora la participación entre & $.0 \%$ & $71.5 \%$ \\
compañeros & $100 \%$ & $.0 \%$ \\
Se pierde tiempo & $100 \%$ & $100 \%$ \\
Total & \multicolumn{2}{|l}{} \\
\hline
\end{tabular}

Fuente: Encuesta a gerentes: incidencia de la comunicación en la productividad en las Pyme del cluster Textil/Confección, Diseño y Moda del área metropolitana de Medellín, Colombia.

Fuentes de información preferidas por los obreros de las Pyme

La comunicación me llega a través del gerente

El $66.7 \%$ de los obreros encuestados manifiesta estar totalmente de acuerdo en que la información le llega a través del gerente y un $26.7 \%$ afirma estar de acuerdo. El gerente es la primera fuente de información para los operarios de las Pyme. Para él, en gran medida, la comunicación es su trabajo, pues continuamente toma información del entorno para distribuirla, compartirla y diseminarla de forma directa con sus empleados.

De igual manera, Mintzberg (1975) sostiene que es un mito pensar que el gerente necesita de un sistema administrativo de información formal para tomar decisio- 
nes; por el contrario, los gerentes están más a favor de los medios verbales, principalmente las llamadas telefónicas y las reuniones, además de que tienen, a su servicio, cinco medios de información: los documentos, las llamadas telefónicas, las reuniones programadas, las reuniones imprevistas y las visitas de observación.

La comunicación me llega a través de mi supervisor

Como segunda fuente de información para los operarios está el supervisor: el 46.7\% de los encuestados dice estar totalmente de acuerdo en que la información le llega a través del supervisor, mientras un 33.3\% dice estar de acuerdo. El supervisor deberá tener la competencia comunicativa de hacerse comprender por parte de operarios y superiores. Las interacciones comunicativas entre el supervisor y los operarios son de doble vía mediante las instrucciones verbales, las reuniones y los informes de resultados.

La comunicación me llega a través de mis compañeros

Como tercera fuente de información para los operarios están los compañeros de trabajo: el $26.67 \%$ de los encuestados dice estar totalmente de acuerdo en que la información le llega a través de los compañeros y un $20 \%$ afirma estar de acuerdo. En las Pyme, conocer más a fondo a los compañeros de trabajo es importante, ya que la mayoría de las veces ellos comparten tiempo; pero casi siempre referido a la relación laboral. Al escuchar a los compañeros acerca de los temas organizacionales y de algunos aspectos del trabajo se aprende de ellos, de sus vivencias, de la forma de afrontar las dificultades, de sus limitaciones y de sus competencias. Según Clampitt y Downs, (1993) la comunicación con compañeros de trabajo es percibida por los operarios como de bajo impacto en la productividad personal.

\section{Conclusiones}

En opinión de los gerentes encuestados, la comunicación sí incide en la productividad de las Pyme del cluster Textil/Confección Diseño y Moda de Medellín, Colombia, al aumentar la productividad, al mejorar la eficiencia y la calidad —ambas son expresiones de la productividad - y al coadyuvar en la planeación más clara de las tareas; de igual forma señalan que la comunicación formal incide más que la informal en la tasa de crecimiento de la productividad; además, también perciben que la interacción comunicativa incide en la productividad mejorando la participa- 
ción entre compañeros y aumentando el compromiso en los grupos de trabajo en las Pyme.

Con relación a los medios de comunicación en las empresas y su incidencia en el crecimiento de la productividad, los gerentes entrevistados perciben que la comunicación personal directa, contacto personal y reunión, son las más importante, seguida por la comunicación personal mediada: correo electrónico y memorando.

Los operarios opinan que la primera fuente de información es el gerente, la segunda es el supervisor y la tercera son los compañeros de trabajo; estos resultados no coinciden, a excepción de los compañeros de trabajo como tercera alternativa, con los estudios de Howard (1998) quien sostiene que investigación tras investigación se demuestra que la primera elección de los operarios como fuente de información es su propio supervisor, el gerente es la segunda alternativa y la tercera elección son los compañeros de trabajo.

Dado el carácter de esta investigación, los hallazgos deben ser tomados con cautela; sin embargo, se considera que los resultados obtenidos en este estudio pueden servir a futuras líneas de investigación que se interesen por abordar el tema de la comunicación y la productividad en las organizaciones. Este trabajo se limita a 17 empresas entrevistadas y, por lo tanto, sus hallazgos no son extensivos a las empresas pequeñas y medianas en Colombia.

\section{Bibliográfias}

Aktouf, O. (1996). La administración: entre tradición y renovación. Cali: Universidad del Valle.

Bain, D. (1993). Productividad, la solución a los problemas de la empresa, México: McGraw-Hill.

Bateson, G. et al. (1994). La nueva comunicación. Barcelona: Kairós.

Blum, M. y J. Naylor (1997). Psicología industrial. México: Trillas.

Chanlat, A. y R. Bedárd (1997). La administración: cuestión de palabra. Tecnología Administrativa, Universidad de Antioquia, XI (25) 
Clampitt, P. y C. W. Downs. (1993). Employee perceptions of the relationship between communication and productivity: a field study. Journal of Business Communication, 30 (1): 5-28. (También disponible en http://postgradicm. wikispaces.com).

Costa, J. (1999). La comunicación en acción. Barcelona: Paidós.

Fayol, H. (1986). Administración industrial y general. Madrid: Orbis.

Fernández, C. (1991). La comunicación en las organizaciones. México: Trillas.

Goffman, I. (2001). La presentación de la persona en la vida cotidiana. Buenos Aires: Amorrortu.

Gusdorf, G. (1957). La palabra. Buenos Aires: Galatea Nueva Visión.

Hellweg, S. y S. L. Phillips. (1982). Communication and productivity in organizations. Public Productivity Review, 6 (4). (Disponible en http://www.jstor. org/stable/3380183).

Howard, C. M. (1998). How your employee communications programs can boost productivity and pride. Public Relations Quarterlyp 43 (3): 15-23.

Kersley, B. y C. Martin (1997). Productivity growth, participation and communication. Scottish Journal of Political Economy (44): 485-501.

Lasswell, H.D. (1948). The structure and function of communication in society. en L. Bryson (ed.), The communication of Ideas, New York, Harper: 37-51.

Lucas, A. et al. (2003). Sociología de la comunicación. Madrid: Trotta.

Miller, K. y P. Monge (1986). Participation, satisfaction, and productivity: a meta-analyitic. The Academy of Management Journal. 29 (4): 727-753

Mintzberg, H. (1975). The manager's job: folklore and fact. Harvard Business, July-August. 
Morin, E. (1993). El método I: la naturaleza de la naturaleza. Madrid: Cátedra.

Múnera, P. (2005). El comunicador corporativo: entre la teoría y la práctica. De la etimología de la comunicación a la organización viable. Medellín: Editorial Zuluaga.

Rizo, M. (2004). El camino hacia la nueva comunicación. Revista Razón y Palabra, 40 Disponible en: http://www.razonypalabra.org.mx/anteriores/n40/ mrizo.html

Van Dijk, T. A. (2000). El discurso como estructura y proceso. Barcelona: Gedisa. 


\section{ANEXO 1 \\ Encuesta a gerentes de las Pymes}

La siguiente encuesta es realizada por el Centro de Investigaciones y Consultorías (CIC) de la Facultad de Ciencias Económicas de la Universidad de Antioquía y con la colaboración de la Subdirección de ACOPI, Antioquía.

Cordialmente solicitamos su colaboración para que responda las siguientes preguntas con la mayor sinceridad. La información que nos proporcione será manejada con la más estricta confidencialidad.

Esta encuesta ha sido elaborada con el fin de conocer su opinión sobre la incidencia de la comunicación en la tasa de crecimiento de la productividad.

1. ¿Cómo incide, en la Pyme, la comunicación en la tasa de crecimiento de la productividad?

2. ¿Cómo se mide la productividad en su empresa?

3. ¿Qué indicadores de calidad tiene su empresa?

4. ¿Qué indicadores de eficiencia tiene su empresa?

5. ¿Qué indicadores de eficacia tiene su empresa?

6. ¿Qué indicadores de efectividad tiene su empresa?

7. ¿Qué clase de comunicación incide más en la tasa de crecimiento de la productividad? (Respuesta única)

La comunicación formal ¿Por qué?

La comunicación informal ¿Por qué?

8. ¿Qué tipo de medios utiliza su Pyme para comunicarse con sus empleados? Jerarquizar de uno a siete en orden de importancia, siete es el más importante y uno el menos importante.

El contacto personal

Memorandos

Boletines

Teléfono

Correo electrónico

Medios audiovisuales

Reuniones 
9. De los anteriores medios de comunicación, ¿cuál (es) pueden ser más impactantes en la incidencia de la tasa de crecimiento de la productividad?

10. ¿La interacción comunicativa que se da — cara a cara — entre compañeros de trabajo incrementa la tasa de crecimiento de la productividad?

Si ¿Por qué? No ¿Por qué?

11. Empresa

12. Profesión

13. Género: M F

Observaciones
14. Cargo

15. Tiempo de vinculación

\section{ANEXO 2 \\ Ecuesta a obreros de las Pymes}

A continuación usted tiene una lista que incluye diferentes aspectos relacionados con la comunicación y la productividad, sobre las que se pregunta por su grado de acuerdo o desacuerdo.

Por favor, proceda a seleccionar la frase marcando con una " $\mathrm{X}$ " sobre la abreviatura correspondiente al frente de la frase, teniendo en cuenta que cada abreviatura quiere decir:

$(\mathrm{TA})=$ Totalmente de acuerdo

$(\mathrm{DA})=$ De acuerdo

$(\mathrm{NINI})=\mathrm{Ni}$ de acuerdo ni en desacuerdo

$($ ENDESA $)=$ En desacuerdo

$(\mathrm{TD})=$ Totalmente en desacuerdo

La comunicación me llega a través del gerente.

La comunicación me llega a través del supervisor.

La comunicación me llega a través del compañero de trabajo.

Datos de clasificación:
Indique su género:
a. Masculino
b. Femenino 
Indique su estado civil:
a.Solter@
b.Casad@
c. Unión libre
d.Viud@
e. Separad@
f. Divorciad@

Indique su nivel de escolaridad:
a. Primaria
b. Secundaria
c. Técnica
d. Tecnológica
e. Universitaria

Indique sus años de vinculación y nombre de la empresa:

Ubique su edad en uno de los siguientes rangos:
a. Menor de 25años
b. Entre 25 y 30 años
c. Entre 31 y 35 años
d. Entre 36 y 40años
e. Mayor de 40 años

Indique su clase de vinculación laboral con la empresa
a. Término indefinido
b. Término Fijo

Observaciones

\section{ANEXO 3 \\ Listado de empresas de ACOPI}

1. Confecciones Jaru, S.A., 2. Confecciones Valen, 3. Guillesport, 4. Saltarines Ltda., 5. Creaciones Alsatex, 6. Productos Infantiles, S.A., 7. Confección Alice y Piolin y Cía., 8. Primordial, S. A., 9. J. DOBLE F. Ltda. - Pucheros, 10. Herrera y Torres Ltda., 11. Gallo Vélez y Cía., Ltda., 12. Toral Ltda., 13. Pop Latinas, 14. Confecciones José Ignacio González, 15. Productora de Moda, 16. Calcetería Herva, S.A., 17. Confecciones Vanyty Ltda., 18. Kaffe prendas íntimas, 19. Acabados Tonos y Colores, 20. Tintorería y Telas Albahaca Ltda., 21. Confecciones, Tejidos y Tintorería Jaydor, 22. Somoscolor, S.A., 23. Fashion Wash Ltda., 24. Ultrabordados Ltda., 25. Tejidos María del Pilar H, 26. Lagobordados, 27. Mercadeo Profesional, 28. Industrias Gomar Ltda., 29. Creaciones y Confecciones Rico, 30. Dicontex Ltda., 31. Xcreencolor, S.A., 32. C.I. Retex, S.A., 33. Tejidos y Confecciones Dino, S.A., 34. Insumos \& Textiles Ltda., 35. Diseños Básicos, S.A., 36. Textiles Papagallo, S.A. ( 